\title{
O Direito Internacional Privado solucionando conflitos de cultura: os divórcios no Japão e seu reconhecimento no Brasil
}

\author{
por Claudia Lima Marques, \\ Professora Titular de Direito Internacional Privado da \\ Universtidade Federal do Rio Grande do Sul, \\ DOUTORA EM Direito pela Universidade dE HEIDELBERG E \\ Mestre em Diretto Crvil e Direito Internacional Privado pela \\ Universidade de Túbingen, Alemanha
}

\section{Introdução}

Anna Maria Villela, a grande professora do Direito Internacional Privado brasileiro, a quem homenageio com este artigo, afirmava que o divórcio pronunciado por um juiz estrangeiro é uma questão antiga no Brasil e que levou o Direito Internacional PrivadoDIPriv. a uma evolução sem precedentes nesta matéria. ${ }^{.}$Também Haroldo Valladão ${ }^{2}$ dedicou um de seus cursos na Academia de Direito Internacional de Haia à dissolução do casamento, demonstrando que mesmo não conhecendo o divórcio até 1977, o Judiciário brasileiro sempre foi muito aberto ao reconhecimento de sentenças estrangeiras de dissolução do casamento, se pelo menos um dos cônjuges eta estrangeiro. ${ }^{3}$

\footnotetext{
' VILLELA, Anna Maria. O divónio no Direito Intornacional Privado. Rio de Janeiro: Forense, 1980, p. 7 e 30.

2 VALLADÃO, Haroido. Conséquences de la differente de nationalité ou de dantioile des époux sur les effets et la dissolution du mamiage, in Recueil des Cours, 1962, t. 105, P. 75 e seg.

${ }^{3}$ De 1916 a 1942 , o Art. 8 da Introdução ao Código civil utilizava o elemento de conexão nacionalidade para reger as questôes de direito de família e depois de 1942 até 1977 , a Lei de Introdução ao Código Civil também utilizava indiretamente este elemento de conexão afirmando: "Art, 7. $\$ 6^{\circ}$. Não será teconhecido no Brasil o divórcio, se os cônjuges forem brasileiros. Se um deles o for, será reconhecido o divórcio quanto ao outro, que não poderá, entretanto, casar-se no Brasil." Assim SAMPAIO, Pedro. Validade das Sentencas de Divárcio no Direito Brasileiro. Rio de Janeiro: Forense, 1973, p. 102. Veja em SAMPAIO, p. 89 e seg, também a reprodução da jurisprudência do Supremo Tribunal Federal antes da introdução do divórcio no Brasil.
} 
Efetivamente, a questão do divórcio esteve por muito tempo relacionada no Brasil a elementos culturais (e jurídicos) específicos, como à forte influência da religião católica no pais $5^{4}$ a ponto de a indissolubilidade do casamento (até 1977$)^{5}$ ou a sua dissolubilidade fazer parte integrante de nossas normas constitucionais, ${ }^{6}$ logo, da ordem pública em DIPtiv. ${ }^{7}$ A famosa Súmula 381, sobre o não reconhecimento de divórcios en foros facilitatórios e por procuração, constitui-se entre nós no maior exemplo de combate à fraude à lei pessoal em nosso Direito Internacional Privado.

Da mesma forma, internacionalmente, o divórcio foi responsável por muitas evoluções na teoria do direito internacional privado, desde a noção de fraude à lei, no famoso caso da princesa Baufremont de 1878, como no que se refere à qualificação entre tegras de fundo e regras de forma e da próptia evolução da noção de ordem pública, positiva e negativa." O famoso caso do casamento espanhol de 1977, que levou à evolução da ordem pública com conteúdo constitucional teve como base a inexistência da instituição do divórcio na Espanha. ${ }^{10} \mathrm{Assim}$ também foram os ritos religiosos de divórcios, como o divórcio judaico, ${ }^{11}$ que fotçaram o Judiciário na Alemanha a reconhecer a necessidade de uma 'tolerância funcional' entre estas entidades e o judiciário laico. ${ }^{12}$ Como ensina o meu mestre de Heidelberg, Erik

${ }^{4}$ Assim SOUZA, Adalberto Pimentel Diniz de. Dissolufano do vinoulo conjugal, in Revista dos Tribunais, v. 741, jul. 1997, p. 747 e seg. $(747-760)$.

5 Por exemplo, a Constituiçäo de 1964 afirmava: "Art. 175.A fantíla é constituida pelo casamento e terá direito à proteção dos Poderes Públicos. $\$ 1^{\circ} \mathrm{O}$ casamento é indissolúvel." in SAMPAIO, p. 102.

"Assim Axt. 226 da Constituição Federal de 1988:

? VILLEY.A, p. 30.

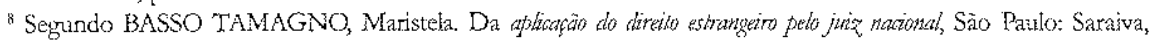
1988 , p. 82, a base da Sútnula 381 foi a seguinte decisão: "Casamento realizado na Itália e divórcio decretada no Mexico. Sentença a que se denegou homologaçāo. Ausência de prova de nacionalidade do marido e do domicilio de ambos os cônjuges, nos dois paises." (STF Sentença Estrangeira n. 1778-México, 1962, Rẹ. Min. Pedro Chaves).

"Assir ensina GAUDLMET-TALLON, Hélène. Lat dísunion du couple af droit international privé, Recueil des Coturs, 1991,1, t. 226, p. 30.

10 Veja sobre este caso e sua infuência na modificação e atualizaçào da lei de introduçāo ao Código Civil alemão (EGBGB) e seu atual Art. 6, LABRUSSE, Catherine, Droit constitutionnel et le droit international privé en Allemagne fédérale- à propos de la décision du Tribunal Constitutionnel fédérale da 4 mars 1971, Ren. Crit. dr. internal prive, 1974, p.1 e seg. Veja também BUCHER, Andreas, La famille en droit intemational privé, Recuell des Cours, tome $283(2000)$, p. 9 e seg.

"Sobre o tema o divórcio judaico e a importânica de conseguir a cartanget, veja Kinhorn, Talia. Jewish Divore in the International Arema, in BASEDOW, J. Private Law in the international Arenawiber Amicorum Kurt Siehr, Haia: T.M.C. Asser Press, 2000, p. 135 e seg.

"Assim reproduz Erik Jayme uma decisão de 1994, a qual afirma que deve o 'tribunal religioso do rabinato' promover o divórcio de judeus nacionais de Israel em solo alemão, havendo possibilidade de reconhecimento, tnas não de 'atuação' do Judiciário alemão pra realizar o divórcio segundo queriam as partes, segunda a lei israeli:"'Eine solche vom jüdischen Reche geforderte Mitwirkung des Rabbinatsgerichts, das das Vorliegen der Scheidungsvoraussetzungen feststelit, ist eine Tätigkeit, die, weil der Rabbiner als Geistlicher tätig wird und sein Mitwirken Teil ciner religiösen Fandlung ist, dem deutschen Rechtssystem völlig wesensfremd ist und von einem deutschen Gericht nicht geleistet werden kann."(KG 11.1.1993, FamRZ 1994, p. 839), in JAYME, Erik, Religiôses Recht wor siatichen Gerichten. Heidelberg: C.Winter, 1999, p.1. Veja também no mesmo sentido decisão de 1998, KG 27.11.1998, in MPRAx 2000, p. 126-128 e seu comentário por HERFAHRT, Christoph, Scheidung nach religtösen Reclat durch deutsche Gerichte, in IPRAX 2000, p. 101-103. 
Jayme, o respeito às diferenças culturais é um valor na pós-modernidade e aparece com extrema clareza em matéria de formas de celebração e formas e causas de dissolução do casamento. ${ }^{13}$

O objetivo deste breve trabalho é pois refletir sobre a pesquisa com casos envolvendo divórcios japoneses no STF de 05 de outubro de 1988 a 22 de agosto de 2002, que realizamos com o nosso Grupo de Pesquisa e que foi publicada na Revista da Faculdade de Direito da UFRGS em setembro de 2002, na Edição especial em homenagem à Cooperação entre a Facullade de Direito da Universidade de Tohoku, Sendai (Japão) e a Faculdade de Direito da UFRGS. ${ }^{14}$ Minha hipótese de trabalho é que aqueles 30 casos ( 23 decisões monocráticas e 7 acórdãos) representam uma amostra significativa de como é entendida a instituição do teconhecimento de sentenças pelo STF, de forma bastante flexivel e aberta para solucionar eventuais conflitos culturais, em especial com países de origem de nossos imigrantes majoritários, como o Japão.

\section{I-Divórcios japoneses no STF: um divórcio consensual e privado reconhecido?}

Segundo o Prof. Dr, Erik Jayme, da Universidade de Heidelberg, Alemanha, em seu ar tigo sobre Direito Comparado pós-moderno, ${ }^{15}$ o direito comparado pós-moderno estaria mais interessado no diferente, no flúdo e especial, aquilo que divide e caracteriza, no atual e específico de cada ordenamento jurídico, a respeitar a identidade social e cultural de cada povo. ${ }^{15}$ Brasil e Japão apresentam duas culturas, dois povos diferentes, dois sistemas jutídicos bastante distintos. Escolher como objeto de pesquisa estas 'diferenças', ${ }^{17}$ especialmente em Direito Internacional de Família, é a finalidade deste pequena reflexão.

Inspirados pelo belo artigo da colega de Sendai, Profa. Dra. Yuko Nishitani, ${ }^{18}$ escolhemos particularmente como objeto de pesquisa os casos de divórcio. Como ensina Muir Watt, ${ }^{19}$ os modelos familiares são afirmações da cultura, do modo de ver os direitos

${ }^{13}$ Jayme, Religiöses Recths, p. 35 e 36.

${ }^{14}$ MARQUES, Claudia Lima, JACQUES, Daniela e SCHMITZ, Maitê, Perguisa de casas envotvendo diturarios japoneser no Supremo Tributul Federal de 05.10.1988 ate 22.08.2002, in Revista da Faculdade de Direito da UFRGS, Edição especial cm homenagern à Cooperação entre a Faculdade de Direito da Universidade de Tohoku, Sendai (Japão) e a Faculdade de Direito da UFRGS, setembro 2002, p. 176 a 219.

${ }^{15}$ Veja JAYME, Lrik, Visöer para una teoria pós-moderna do direito comparado, in Revista dos Tribunais (São Paulo), nr. 759 , p. 24 a 40.

${ }^{16}$ Veja meu artigo, Notas sobre a sistema de proibiçäo de clibusulas abusizar no Código Brasileiro de Defesa do Consumidor (Entre a tradicional permeabilidade da ordem juridica e o futuro púsmoderno do direito comparado), in RTDC vol. 1 , jan/mat. 2000 , p. 13 a 58.

${ }^{17}$ JAYME, RT 759, p. 25: "A minha Tese printipal te a seguinte: $O$ stiveito comparato moderno perseguia o objetivo, de seterninar, de encmitrar o que era comms, igual (das Gemeinsane), e que apenas superficionalmente podia aparecer e ser.

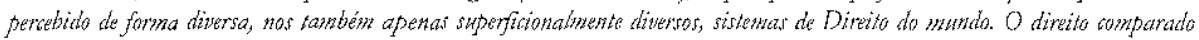

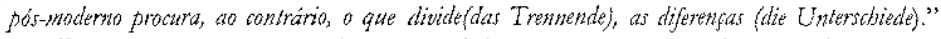

${ }^{18}$ NISHITANT, Yuko, Privat- und Schlichtungsscbeidlung deutstber Statsangeböriger in Japan und die Schtedtungsanterkennung in Deutschland, ir IPRAX 2002, p. 49-53.

"MUIR WATT, Horatia, Les modèles familiaus à l'éprcuve de la mondialisation (aspects de droit international privé), Arch. phil. droit 45 (2001), p. 271 (pp. 271-284). 
humanos, e, em especial, a atual desagtegação da família nas relações privadas internacionais é um grande desafio pata o Direito Intetnacional Ptivado do mundo globalizado.

O divótcio realizado em um país, por exemplo no Japão, por um Nisei (segunda geração de imigrantes) brasileiro que lá teside para trabalhar em uma fábrica e reconhecido em outro, por exemplo, o Btasil onde o outro cônjuge reside com os fllhos, determina a modificação do estado civil destes imigrantes, brasileitos ou japoneses, permite um novo casamento e leva a regulação dos deveres alimentares entte cônjuges e em relação à eventual prole. ${ }^{20}$ Vejamos então os tipos de divórcio japoneses e comparemos as normas japonesas aplicadas nestes casos às btasileiras e européias.

\section{A - Os tipos de divórcio no Direito Japonês e sua utilização no Japão}

Face a cultura japonesa, - de resolver de forma interna e discreta- os problemas familiares, não é de espantar que existam no país duas 'formas' privadas consensuais ou mediadas de dissolução do casamento, sem qualquer presença do Estado no que se refere à declaração de vontade, que é apenas comunicada através do registro a posteriori no cadastro administrativo do prefeito ou do distrito ou vila rutal (Art. 1 e 16 do Kosekibô. ${ }^{21}$

Efetivamente, o Código Civil Japonês (Kasai Geppô) prevê, do Art. 763 ao Art. 768, estas formas de divórcio consensual, seja por aceitação simples de uma das partes da 'declaração de divórcio' pelo outro (art. 765), ${ }^{22}$ seja por mediação por terceiro, em casos mais complexos, scja mediação voluntária ou obrigatória (que Nishitani denomina Scblicbtungs- und Zwangschblicbtungsscheidung. ${ }^{23} \mathrm{O}$ divórcio judicial, com auxilio do juiz, está previsto nos Art. 770 a 791 e é efetuado frente à Corte de família. O Art. 819 do Código civil japonês estabelece as regras sobre guarda de menores e registro no cadastro de família. ${ }^{24}$

Interessa-nos aqui as díferenças culturais, nós brasileiros acostumados ao litígio e a discussão da culpa no divórcio e a longas e amplas ações de separação e de divórcio onde todos os detalhes da vida em comum pregressa são examinados. No Japão as diferenças são enormes, totalizando as formas de divórcio consensual 99\% dos casos. Assim, em 1999, $91,46 \%$ dos divórcios realizados no Japão foram divórcios "privados", extrajudiciais conforme

${ }^{20}$ Assim ensina FERNANDEZ ARROYO, Diego et allii, Derecho Internacional privado de los Estatos det Mercosur, Ed. Zavalia, Buenos Aires, p. 749 e seg.

${ }^{21}$ Segundo gentil traduçāo de Tomoko Gaudioso, o texto do Art. 1 do Kaseki brou é: Art. 1 [ Controle e administração referente ao cadastrol, $\$ 1^{\circ}$. O serviço referente ao cadastro de familia é efetuado pelos órgãos estabelecidos por prefeitos, representante do distrito e por representantes das comunidades rurais(vilas)." Já Nishitani, IPRAX 2002, p. 49, denomina esta lei de Lei sobre o registro familiar (Gesetz über das Familienbuch) e kosekishô, que aqui utilizaremos.

${ }^{22}$ A gertil tradução de Tomoko Gaudioso deste texto é a seguinte: "Art. 765 [A aceitação da declaração de divórcio] $\$ 1$. A aceitação da declaração do divórcio somente ocorrerá após verificar que a mesmo não viola o $\$ 2$ do Art. $739, \$ 1^{\circ}$ do Art. 819 e outras leis. $\$ 2^{\circ}$. Se a aceitação da declaração for efetuada por vício, omitindo o que foi estabelecido no $\$ 1^{\circ}$, mesmo assim, o seu efeito permanecerá."

${ }^{23}$ NISHITANI, IPRax 2002, p. 50.

${ }^{24}$ Veja,por todos, MARUTSCHKE, Einführung in das japanische Recht, Munique, Beck, 1999, p. 2 e seg. 
determina o $\$ 764$ c/c $\$ 739$ do Código Civil Japonês (Kasai Geppô), já 7,73\% dos divórcios ocorrem por arbitragem/mediação e somente $0,81 \%$ através de decisões judiciais stricto sensu. ${ }^{25}$ Em seu texto de 2002, Nishitani adiciona ainda mais dados, informando que em 1997 e 1998, 90,93\% dos divórcios no Japão eram privados, somente $8,24 \%$ ocorreram por mediação voluntária e $0,4 \%$ por mediação imposta e $0,80 \%$ apenas eram divórcios judiciais. ${ }^{26}$

São estes divórcios "privados" japoneses que devem ser teconhecidos no Brasil, especialmente pelo Supremo Tribunal Federal nos 30 casos analisados pelo STF em nossa pesquisa, assim interessa-nos saber se há realmente esta natureza "administrativa" visualizada pelo STF nos casos ou se, em contrário, a sua natureza "privada" impediria o seu reconhecimento no Brasil.

Em sua palestra de 2001, a professora Nishitani resumiu as regras sobre o Divórcio no Direito Japonês da seguinte forma: "O Código Civil Japonês (CCJ, Kasai Geppố) prevê o Divórcio privado e o divórcio judicial. A lei sobre Decisões em Matéria Familiar (LDMF, kaji shinpanhô) prevê o divórcio arbirral (administrativo) voluntário e o divórcio arbitral imperativo. Assim temos:

(1) Divórcio privado ( $\$ 764$ e 739 CCJ) $\rightarrow$ Deve ser registrado no "registro familiar" (koseki) conforme a Lei sobre o Registro Familiar (kosekibô)

(2) divótcio arbitral é feito no tribunal familiar (administrativo) (Prioridade do arbitramento por mediadores em caso de näo consenso: Art. 18,1 LDMF)

(3) divórcio arbitral imperativo (sobre a base do arbitramento e mediação) frente ao Tribunal (administrativo) de Familia (Art. 24 LDMF) $\rightarrow$ Há possibilidade de recurso

(4) Divórcio Judicial frente ao Juiz distrital (Processo normal segundo o Artigos 1 e seguintes da Lei processual sobre processos envolvendo direitos individuais-LPDI, jinji soshô tetsuqukihố), quando um dos motivos de divórcio do $\$ 770,1 \mathrm{CCJ}$ está presente. Há um maior espaço de convencimento e decisão para o Juiz, mas a previsibilidade da decisão é pequena."

De outro lado, no Brasil, o divórcio, como instituição, foi uma das mais polêmicas; instituição desconhecida no ordenamento jurídico brasileiro até 1977, alcançou hierarquia constitucional (sua proibição e sua liberalização), sofreu vários limites e integra hoje, sem dúvida alguma, a ordem pública em DIP, ${ }^{27}$ daí a importância de aprofundarmos a análise de uma eventual violação de nossa ordem pública por estes tipos de divórcio.

${ }^{25}$ Dados levantados por Yuko Nishitani, em 1999, em sua palestra na UFRGS, veja Jinkô Dôtai Chôsa 1999 (http://wwrwdbtk.mbw.go.jp/toukei/data/010/1999/tokeihyou/0002674/ t0048025/ml...)

26 NISHITANI, IPRax 2002, p. 49.

${ }^{27}$ Veja DOLNGER, Jacob, Evolustion of principles for resolving conflicts in the field of contracts and torts, in Recueil, vol. 283 (2000), p. 291 e seg. 


\section{B-Comparando a função dos divórcios privados japoneses com os divórcios brasileiros; um problema de ordem pública?}

Mister inicialmente examinar algumas normas japonesas de Direito Internacional Privado, na lei especial de DIPriv. denominada Horei. ${ }^{25}$ Segundo o Art. 3 da Horei, a capacidade das pessoas (no caso os japoneses ou brasileiros que divorciam-se no Japão) é regulada pela lei de sua nacionalidade, japonesa ou brasileira. ${ }^{29}$ Neste sentido, relembre-se que muitos dos Nisei brasileiros que retornam para o Japão e lá se divorciam dos conjuges domiciliados no Brasil são brasileiros e não mais japoneses segundo as leis de nacionalidade japonesas, dai poder ser aplicado a este divórcio a lei brasileira! Quanto à forma, o Horei apresenta uma regra geral em seu Art. 8 que manda aplicar a lei principal (lex causae) que regulará os 'efeitos do negócio jurídico, ${ }^{30}$ Neste caso, se o divórcio privado for considerado pelo STF como apenas um problema de forma e não como de mérito, aplicável é a lei principal do divórcio (lex causae), a japonesa ou a brasileira.

A lei principal que regula os divórcios realizados no Japão está determinada pelo Art. 16 do Horei. Aplicável seria a lei que regula o casamento (envio para o art 14 do Horei), mas se um dos cônjuges é de nacionalidade japonesa ou possui à época do divórcio sua residência habitual no Japão, aplicável é a lei japonesa. ${ }^{31}$

Yuko Nishitani, em sua palestra na UFRGS em de 2001, assim também concluia que, caso um dos 220 mil brasileiros que vivem atualmente no Japão queira divorciar-se, será possivelmente declarado aplicável para este divórcio o direito japonês, face aos elementos de conexão escolhidos pela lei japonesa e afirmava: "A lei aplicável ao divórcio (estatuto do divórcio) segundo o Direito Inrernacional Privado japonês é a seguinte: Art. 16, 1 da Lei de Direito Internacional Privado/ Horei, que apresenta uma conexão em cascata $\left(1^{\circ}\right.$. elemento de conexão: a lei nacional comum; $2^{a}$ conexão: a lei do lugar de residência habitual comum; $3^{a}$ conexão: a lei mais conectada com o caso concreto/lei mais próxina do caso) e Art. 16,2 Horei: Se um dos cônjuges tem a nacionalidade japonesa e a sua residência habitual no Japão, aplicar-se-á a lei japonesa (denominada cláusula de "favor japonêes")."

Mister, pois, analisar as crítcas que os próprios autores japoneses tecem com referência ao direito japonês do divórcio consensual. Yuko Nishitani alerta que, como a declaração de divórcio inicia de forma unilateral (Scheidungformular), geralmente pelo marido e como os japoneses não conhecem a assinatura, mas se utilizam para esta função de carimbos

${ }^{28}$ Utilizarei a tradução da Horei (Gesetz betreffend die Anwendung der Gesetze) realizada pelo Instituto Max-Planck de Hamburgo, in KROPHOLLER, Jan et allii, Ansserenropäische IPR-Gesetze, Dd. DNotl/Max Planck-lnstitut, Hamburgo, 1999, p. 308 a 318.

29) Horei, in KROPHOLLER, p. 308.

3.) Horei, in KROPHOLLER, P. 310.

3 "Art. 16. [Ehescheidung] die Bestimmungen des Art. 14 gelten entsprechend für die Ehescheidung. Ist jedoch einer der ehegatten Japaner und hat seinen gewöhnlichen Aufenthalt in Japan, so richtet sich die Scheidung nach japanischen Recht." Horet, in KROPHOLEER, p. 313. 
(familiares!), há muita probabilidade de falseamento desta declaração de 'aceitação' do divórcio. A ponto de existir um instrumento para evitar que um cônjuge possa 'declarar' o divórcio consensual sem o consentimento ou conhecimento do outro. Desde 1952, o ministério da justiça desenvolveu um diretiva que permite a qualquer dos cônjuges realizar uma declaração no Registro de Famillia ou Corte familiar denominada : "Declaração cautelar de não aceitação da declaração de divórcio privado' (vorsoglichen Antrag auf Nicbiannabme des Scheidung.formulars). ${ }^{32}$ informa que anualmente cerca de 25 mil pessoas fazem uso deste instrumento preventivo no Japão. ${ }^{33}$

Esta autora japonesa vai mais longe, afirmando que mesmo se o cônjuge mulher realmente consentir na declaração de divórcio do marido, pode esta estar sendo tratada de forma 'abusiva' aos olhos ocidentais, pois nesta declaração a parte econômica da dissolução é tratada e na maioria das vezes com renúncia a direitos patrimoniats. ${ }^{3 .}$ Para se rer uma idéia da força desta observação da autora japonesa, mister ponderar que segundo o Art. 762 do Código Civil japonês, o regime de bens legal já é o da separação absoluta de bens e, anualmente, apenas 15 casais optam no Japão por outro regime de bens mais favorável às mulheres. ${ }^{35}$ Informa também que, em $50 \%$ dos divórcios privados, os alimentos para a mulher não são concedidos e que em $80 \%$ dos divórcios, o tema dos alimentos para os filhos sequer é tratado nesta declaração de divórcio ! ${ }^{36}$

Sendo assim Yuko Nishitani defende, em seu artigo de 2002, que as 'declarações de divótcio' consensual mesmo que registradas não equivalem funcionalmente às decisões judiciais ou sentenças (Urteil) ou aos atos oficiais (Hobeitsaktess), como é exigido pelo direito alemão (\$328 ZPO), que está analisando. ${ }^{37}$ A mesma conclusão poderia chegar se analisa-se o direito brasileiro. A doutrina alemã os reconhece apenas como 'negócios jurídicos'. ${ }^{38}$ Para a autora o divórcio mediado, ao contrário, preenche funcionalmente os requisitos, pois o mediador cuida para que o cônjuge mais fraco receba um tratamento econômico correto; assim também um divórcio frente ao juiz japonês pode e deve ser reconhecido em outros paises. ${ }^{39}$

Em resumo, é grande a probabilidade que se aplique a lei japonesa aos divórcios de brasileiros de origem japonesa residentes habitualmente no Japão e que este seja um divórcio privado, consensual, por declaração. Melhor seria que nestes casos, quando o cônjuge sabe que deverá reconhecer o divórcio no Brasil que escolhesse a via do divórcio por atbitragem/

\footnotetext{
${ }^{32}$ NISHITANI, IPRax 2002, p. 49.

${ }^{33}$ NISHITANI, IPRax 2002, p. 49.

${ }^{34}$ NISHITANI, IPRax 2002, p. 49.

${ }^{35}$ NISHITANI, IPRax 2002, p. 49.

${ }^{36}$ NISHITANI, IPRax 2002, p. 49 e nota de estatística de MrZUNO de 1978, nota 9.

${ }^{37}$ NISHITANI, IPRax 2002, p. 52.

${ }^{38}$ NISHITANI, XPRax 2002, p. 52, citando os principais comentaristas Kegel/Schurig, Palandt/ Helderich, Soergel/Schurig e Staudinger/Spellbernberg e decisão que não reconheceu um divórcio privado japonês, pois aplicável era a lei alemãa, BGH 21 2,1990 (BGHZ 110,267).

${ }^{39}$ NISHITANI, IPRax 2002, p. 53.
} 
mediação ou judicial, que não teria nenhum problema de ser reconhecido pelo Supremo Tribunal Federal. Efetivamente, as observações tealizadas por Yuko Nishitani sobre as várias possibilidades de fraude e as dificuldades referentes aos divórcios consensuais japoneses relevam um problema sério de determinar se há ou não ofensa a nossa ordem pública e qual a natureza destes divórcios. O Supremo Tribunal Federal tem considerado todos estes casos como divórcios 'administrativos' e os reconhecido sem maiores problemas, sendo que a problemática da ordem pública sequer é mencionada e o único motivo usado para recusat homologação é a competência absoluta do juízo brasileiro, envolvendo divórcio de nacionais japoneses domiciliados no Brasil, mas proferido no Paraguai. ${ }^{\text {th }}$ Daj a necessidade de passarmos ao exame dos casos ocorridos no STF.

\section{II - O reconhecimento dos divórcios consensuais japoneses pelo Supremo Tribunal Federal}

Segundo demonstrou nosso levantamento dos 30 casos de divórcios japoneses reconhecidos pelo STF desde a entrada em vigor da Consrituição de 1988 até agosto de 2002, o STF não demonstra qualquer dificuldade em reconhecer estes divórcios privados e afirma: “É certo prever o artigo 102, inciso I, alínea 'h', da Constituição Federal a competência do Supremo Tribunal Federal para processar e julgar, originalmente, a homologação de sentenças estrangeiras. todavia, há de adotar"se interpretação aditiva, vislumbrando-se, na referência a sentenças estrangeiras, documentos que, segundo a legislação da origem, tenham tal envergadura. É o caso do ato administrativo de divórcio. No Japão, o desenlace matrimonial não é alcançado via sentença, mas mediante o registro no cartório competente, atuando o administrador do distrito."

Efetivamente, a Constituição Federal no seu art.102, inciso I, alinea " $h$ " estabelece a competência do STF para processar e julgar a homologação de sentenças estrangeiras e, segundo esta inrerpretação majoritária, estaria inserido nesse conceito, qualçuer documento que segundo a legislação da origem do país se tenha como funcionalmente válido para decretar o divórcio. Efetivamente, mesmo antes da introdução do divórcio no Brasil, em 1977, o STF reconhecia divórcios proferidos no exterior de estrangeiros, afirmando: "Homologa-se o divótcio se foi feito com as formalidades de seu país de origem." (STF, SE 1382-Noruega). ${ }^{42}$ Vejamos o direito brasileiro sobre o tema.

\section{A- O Processo de delibação adaptado aos divórcios privados japoneses}

O reconhecimento das decisões estrangeiras é uma parte importante do Direito Internacional Privado ou do Processo civil Internacional, visando justamente garantir o

40 MARQUES/JACQUES/SCHMIDT, p. 218-219.

${ }^{41}$ Assim decisão na SE 7039/JA, Min. Marco Aurélio, j. 20.03.2002, in MARQUES/JACQUES/ SCHMIDT, p. 185.

${ }^{42}$ SAMPAIO, p. 97. 
atendimento das finalidades de harmonia internacional de decisões almejada por estas disciplinas. Visa igualmente dar às partes a segurança jurídica através da circulação dos julgados e aros, o teconhecimento dos direitos adquiridos e situaçôes jutidicamente constituídas no exterior. Como ensina o grande mestre português, também recentemente falecido, Antonio Marques dos Santos: "o fundamento do reconbecimento das sentenças estrangeiras éa continuidade das situaföes juridico-privadas internacionais, a sua previsibilidade, a segurancajurídica que deriva da atuaçäa consoante às expectativas fundadas dos sujeitos de direitos: trata-se pois de justiga formal, própria do Direito Internacional Privado..." 4.3

Cerro é que as decisões (privadas, administrativas ou judiciais) necessitam de homologação pelo Supremo Tribunal Federal, no sistema do direito brasileiro atual, não podendo ser averbadas diretamente. ${ }^{+4} \mathrm{O}$ art. 483 do Código de Processo Civil dispõe que: "a sentença proferida por Tribunal Estrangeiro não terá eficácia no Brasil se não depois de homologada pelo Supremo Tribunal Federal." Como ensina Rechsteiner, ${ }^{45}$ mesmo realizadas frente a um órgão administrativo as decisões de divórcio estrangeiras por mútuo consentimento podem ser reconhecidas no Brasil, se "em conformidade com o sistema jurídico do país de origem". A doutrina brasileira sempre foi bastante positiva e flexível em relação a decisões administrativas, arbitrais e mesmo religiosas, afirmando Pontes de Miranda: "Na expressão sentenças estrangeiras compreendem-se todas as decisões judiciais que precisam ter eficácia alhures desde que decisão cível ou com eficácia cível. Incluem-se as decisões arbitrais e as autoridades administrativas, sem tem eficácia cível." ${ }^{46}$

O sistema seguido pelo direito brasileiro é o da delibação. Seguindo o modelo italiano antigo, realiza o STF somente um juizo de delibação scm avaliar, no entanto, o mérito da decisão estrangeira a ser homologada. ${ }^{47}$ Esse juižo de delibafăo visa assegurar que a decisão estrangeira preencheu os requisitos de homologabilidade exigidos pela legislação brasileira

${ }^{43}$ MARQULS DOS SANTOS, Antonio. Estudos de Diteito Internacional Privado e de Direito Processual Civil Intemacional, Coimbra, Almedina, 1998, p.309.

${ }^{44}$ Assim decidiu o STF na Petiçao avulsa nr. 11: "Sentença estrangeira de divórcio. Pedido de averbação desse ato sentencial dirigido a magistrado estadual. Alegada desnecessidade de prévia homologação, em face do art. 15, parăgrafo único da LICC. Norma legral derrogada pelo CPC (art. 483). Magistério da doutrina. Impossibilidade processual da instauração de delibação incidente. Ação de homologação de sentença estrangeira. Sistema de contenciosidade limitada. Evolução do instituto no direito brasileito. Indispensabilidade da homologação prévia de qualquer sentença estrangeira, quaisquer que sejam os efeitos postulados pela parte interessada. Precedente do STF,

${ }^{45}$ RECHESTEXNER, Beat Walter. Direito Internacional Privado, São Paulo: Saraiva, 1996, p.202.

4i PONTES DE MIRANDA, Francisco Cavalcanti. Comentários ao Código de Processo Civil, Tomo V, Rio de Janeiro, Ed. Forense, 1974, p.90.

${ }^{47}$ Assim DOLINGER, Jacob; "Brazilian Confirmation of Foreign Judgments" in International Lawyer; USA; ABA; 1985; Vol. 19, Number 3; p. 854. Explica Dolinger neste trabalho que: "Brazil has followed the Italian system of giudizio di deibazione, which limits the scope of judicial inquity to form, not substance. Courts review judgments for their external, formal requisites, without any kind of reexamination of the merits of the foreign judgment. While the Italian Cade of Civil Procedure provides an exception of this rule, Brazil has remained more loyal to the system of delibazione." 
não existindo ofensa à ordem pública, à soberania nacional ou aos bons costumes ${ }^{48} \mathrm{Como}$ vimos, segundo o STF o simples fato do divórcio ser realizado frente a um órgão administrativo (por mediação estatal, por exemplo), frente a um tribunal religioso ou um árbitro/mediador, não ofende a ordem pública brasileira. Ao contrário, parece haver após 1977, uma cspírito brasileiro de 'favor divórcio' em nossa ordem pública. ${ }^{49}$ A pergunta é se o divórcio 'amigável' ou consensual apenas registrado pelo Prefeito municipal, como no Japão, ofende a nossa ordem pública. Pedro Sampaio em sua obra de 1973, logo, anterior à introdução do divórcio no Brasil, já afirmava que não: "Homologa-se o divórcio amigável registrado no Japão pelo Prefeito municipal. a lei deste país reconhece como legal o divórcio consensual processado nessas condições", ${ }^{50}$

O mestre portuguess Álvaro da Costa Machado Villela, elogiava o direito brasileiro afirmando: "O único sistema lógico é o sistema da delibação, enquanto reconhece a decisão do tribunal estrangeiro e limita os poderes do tribunal do exequatur a um exame formal, para verificar se trata-se de uma sentença regulat e definitiva, revestida de autenticidade, proferida por tribunal competente não contrária às leis locais de interesse e ordem pública. Com efeito, em face do tespeito devido às jurisdições internacionalmente competentes para decidir as questões entre particulares, o tribunal do exequatur não deve apreciar o mérito da decisão." ${ }^{51}$

Interessante destacar que este autor português preocupou-se com a análise dos efeitos que podem ter a decisão estrangeira, mesmo declaratória de divórcio, a ser homologada c ensina: "Sob dois aspectos gerais uma sentença estrangeira pode ser invocada: ou como ato de jurisdição que declatou um direito de modo definitivo; ou como um simplex documento donde consta a verificação de um fato ou de um direito". E continua: "quando a sentença estrangeira é invocada como ato de jurisdição, ainda o pode ser para um de dois fins: ou para servit de titulo executivo numa execução forçada; ou para produzir qualquer outro efeito inerente ao caso julgado, como para fazer um registro predial ou para deduzir a exceção de caso julgado." "52 Aqui uma observação importante, pois o efeito da homologação da declatação

${ }^{4}$ Veja Sentença Estrangeira Contestada no 5093. Origem: LUA. Publicação: DJ 13/12/1996. Observação: Votaçäo Unânime. Resultado: Deferido, Min. Celso de Mello: "Ementa: ... A Homologação pelo S.T.F. constitui pressuposto de eficácia das sentenças proferidas por tribunais cstrangeiros. - As sentenças proferidas por tribunais estrangeiros somente terão eficácia no Brasil depois de homologadas pelo Supremo Tribunal Federal. O processo de homologação desempenha, perante o Supremo Tribunal Federal - que é o Tribunal do foto -, uma funçâo essencial na outorga de eficácia às sentenças enanadas de Estacios estrangciros. Esse processo homologatório - que se reveste de caráter constitutivo - faz instaurar, perante o Supreno Tribunal Federal, uma situação de contenciosidade limitadia. Destina-se a ensejar a verificação de determinados requisitos fixados pelo ordenamento positivo nacional, propiciando, desse modo, o reconhecimento, pelo Estado brasieiro, de sentenças estrangeiras, com o objetivo de viabilizar a produçăo dos efeitos jurídicos que thes são inetentes..."

${ }^{49}$ Veja neste sentido, sobre a 'incosntitucionalidade' de certos limites ao divórcio, ORESI DA COSTA, Carlos Celso, Tratado do Casamenta e do Divórió, 2.vol, São Paulo, Sarajvâ, 1987, p. 977 e seg.

${ }^{50}$ SAMPAIO, p. 97, citando STF, SE 1312.Japão.

3 MACHADO VILLELA, Alvaro da Costa, O Direito International Privado no Código Cituit Brasileiro, Coimbra, Imprensa da Universidade, 1921, p. 505.

${ }^{52}$ MACHADO VILLELA, p. 505. 
registrada de divórcio no Japão é apenas declaratótio no tertitótio brasileiro, a indicar que realmente a visão positiva do direito brasileiro em relação às diferenças culturais Brasil-japão, pode indicar um caminho certo: harmonia internacional de decisões e respeito às diferenças culturais!

Os requisitos formais necessários para o Supremo Tribunal Federal conceder uma homologação, são, segundo os artigos 216 e 217 do Regimento Interno do STF, os seguintes: a) competência do juiz prolator; b) citação do réu; c) trânsito em julgado do ato sentencial; e d) autenticidade e tradução por tradutor juramentado. ${ }^{53} \mathrm{Os}$ demais requisitos encontram-se repetidos no Art. 15 da LICC/ 42 e Art. 483 do CPC e são todos voltados para sentenças ou decisões de instâncias públicas. ${ }^{54}$ As críticas de Yuko Nishitani, quanto a não equivalência funcional dos divórcios privados japoneses às sentenças teriam aqui sua importância. A tradição do STF é em sentido oposto, bastante flexível. De um lado o tribunal geralmente não permite alargar as discussões no processo delibatótio e usa uma ordem pública processual bastante restrita ${ }^{55}$ de outro lado, sempre mostrou-se aberto a reconhecer divórcios nãojudiciais, desde que de acordo com a cultura local, seja quando estivesse presente alguma autoridade administrativa registrador $a^{56}$ ou mesmo religiosa. ${ }^{57}$

5.3 Barbosa Moreira, José Carlos; Comentánios ao Código de Processo Cimil: Vol. 5, Arls. 476 a 565, llio de Janeiro, Forense, 1998, p. $59-60$.

${ }^{54}$ Veja tambern Art. 483 do C.P.C. e R.I.S.T.F., art. 217, II (teren sido as partes citadas ou haver-se legalmente verificado a revelia), III (ter passado etr julgado e estar revestida das formalidades necessárias à execução no lugar em que foi proferida) e IV (estar autenticada pelo cônsul brasileiro e acompanhada de tradução oficial), além do requisito da negativa de ofensa à soberania nacional, à orden pública e aos bons costumes (art. 216 do R.I.S.T.F). Veja, também, o artigo 15 da LICC.

3s Veja Sentença Estrangeira Contestada no 4795. Origen: Súça. Publicaçâo: DJ 20/10/1995. Julgamento: 16/08/1995. Observação: Votação Unànime. Resultado: Deferido, Min. Maurício Correa: "Ementa: Sentença Estrangeira Contestada. Divórcio. Homologação. O art. 221 do Regimento Interno do Supremo Tribunal Federal delimita o campo para que se estabeleça eventual contraditório, não sendo possivel, pela via processual de sentença estrangeira, discutir situaçōes jurídicas diversas dos requisitos indispensáveis a homologação. Preenchidos os teq̧uisitos regimentais, defere-se o pedido de homologação da sentença estrangeira."

${ }^{56}$ Assim BASSO TAMAGNO, p. 86 e 87, cita o reconhecimento de decisão de divórcio decretado por autoridade admitnistrativa da Noruega, Sentença Estrangeira n. 3.168, Noruega, 20.05.1983, Rel. Mirł. Cordeiro Guerra.

57 Assin BASSO TAMAGNO, p.87 e 89, cita o reconhecimento de decisão de divórcio decretado por rabino em Israel, Sentença Listrangeira n. 3.584, Istael, 15.08.1985, Rel. Min. Moreira Alves. 


\section{B- As regras thateriais e de Direito Internacional Privado brasileiras}

O novo Código Civil de 2002 regula a dissolução do casamento pelo divórcio nos Art.1.571 e seguintes ${ }^{58}$ As tegras determinam os efeitos da separação e do divótcio, no que se refere ao nome, a guarda dos filhos, direito de visitas, aos alimentos ao cônjuge e aos filhos e a partilha de bens. ${ }^{59}$ Preocupa-se também com o registro do estado civil de divorciado, afirmando: "Art. 10. Far-se-á averbação em registro público: I - das sentenças que decretarem a nulidade ou anulação do casamento, o divório, a separação judicial e o restabelecimento da sociedade conjugal". Trata-se de requisito para a habilitação para novo casamento. ${ }^{60}$

No Direito Internacional Privado, o Art. 7 da LICC/ 42 dispõe: "A lei do país em que for domiciliada a pessoa determina as regras sobre o começo e o fim da personalidade, $O$ nome, a capacidade e os direitos de familia." ${ }^{\prime \prime 1}$ O $\$ 6^{\circ}$ do Art. $7^{\circ}$ da LICC $/ 42$ refere-se à homologação de sentenças de divórcio de brasileiros, impondo os mesmos prazos da lei do divórcio de 1977. Seu espírito é positivo para a homologação destas sentenças.

Não há unanimidade entre os autores brasileiros qual a lei indicada aplicável para o divórcio de estrangeiros no Brasil, se a do domićlio conjugal, segundo o Art. $7^{\circ}$ caput como lei geral para os direitos de família, ${ }^{12}$ ou, como parte da douttina defende, a lei da nacionalidade comum destes cônjuges, em interpretação do $\$ 6^{\circ}$ do Art. $7^{\circ}$ da LICC $/ 42$ como estabelecendo o elemento de conexão nacionalidade. ${ }^{63}$

${ }^{58}$ Assim o texto: "Art. 1.571. A sociedade conjugal termina: 1 - pela morte de um dos cônjuges; II -

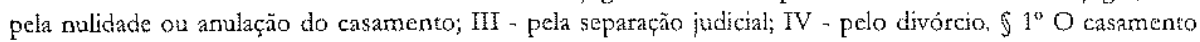
válido só se dissolve pela morte de um dos cònjuges ou pelo divórcio, aplicando-se a presunção estabelecida neste Código quanto ao ausente. $₫ 2^{\circ}$ Dissolvido o casamento pelo divórcio direto ou par conversão, o conjuge poderá manter o nome de casado; salvo, no segundo caso, dispondo em contrátio a sentença de separação judicial."

5.) Veja resumo do conteúdo destas normas dos Art. 1571 a 1582 in SENISE LISBOA, Roberto, Manual Elementar de Direito Civil, vol. 5 - Direito de Familia e Sucessões. 2. ed., São Paulo:Ld. Revista dos Tributrais, 2002, p. 126-133.

${ }^{60}$ Assim o texto: "Art. 1.525. O requerimento de habilitação paxa o casamento será firmado por ambos os nubentes, de próptio punho, ou, a seu pedido, por procurador, e deve ser instruído com os seguintes documentos:...V - certidão de óbito do cônjuge falecido, de sentença declaratória de nulidade ou de anulação de casamento, transitada em julgado, ou do registro da sentença de divórcio."

${ }^{61}$ O Código Bustamante de 1928 dispunha: "Artigo 52. O direito à separação de corpos e ao divórcio regula-se pela lei do domićlio conjugal, mas não se pode fundar em causas anteriores à aquisição do dito domicílio se as não autorizar, com iguais efeitos, a lei pessoal de ambos os cônjuges"

${ }^{62}$ Assim opinião de VILLLLLA, p. 24 e seg. e p. 66 e seg. a quem seguimos nesta opinião, uma vez que utiliza a separação judicial como parâmetro..

${ }^{63}$ Nesta linha de pensamento encontrava-se o grande Hatoldo Valladão, veja revisão de toda a a literatura brasileira de DIPRiv. da época, in VLLLELA, p. 20 a 24. 


\section{Conclusão}

Segundo ensina Anna Maria Villela, o controle exercido pelo STF em matéria de homologação de sentenças estrangeiras de divórcio é "um controle puramente formal ou exterior da decisão estrangeira". ${ }^{44}$ As decisões anteriores à 1977, oriundas dos países nórdicos, como Noruega, Dinamarca e outros, que conhecem decisões administrativas de divórcio, bem demonstram que o STF procura respeitar estas 'formalidades' de celebração do divórcio. Já os divórcios religiosos são mais controlados, no que se refere aos direitos fundamentais das mulheres e à ofensa eventual a nossa ordem pública. ${ }^{65}$

Conclui-se que o divórcio japonês registrado frente a um oficial administrativo é visto mais como uma formalidade do que como um momento de fundo e o controle exercido é realmente meramente formal. Os alertas dos professores japoneses podem servir para levar à evolução da posição do STF, aproximando-a mais da alemã. A verdade é que a posição do STF parece bastante condizente com o momento atual de liberdade dos indivíduos e de circulação de decisões de divótcios, criando maior harmonia e permitindo o reconhecimento das novas famílias formadas após o divórcio em um dos países. Sendo assim, se bem que considero importante a precisão de que se tratam de meros atos privados, registrados no oficial do distrito, mister considerar que se este tipo de divórcio japonês equivale a mais de $90 \%$ do divórcio no país, significa que culturalmente é esta a forma de dissolução do casamento mais aprovada pela população. A regra de reconhecerem-se tais divórcios parece pois contribuir ao entendimento entre Brasil e Japão e a movimentação dos imigrantes e descendentes entre estes paises. As exceções, quando o cônjuge mulher, por exemplo, não tiver realmente consentido ou a declaração lhe tiver retirados direitos, podem ser resolvidas através de um exame mais detalhado no sistema da Sentença Estrangeira contestada, aqui, pelo prejudicado. Concluo ,pois, louvando a linha de nosso Supremo Tribunal Federal que souhe respeitar as diferenças culturais de ambos os países e fomentar a harmonia de decisões entre estes.

\footnotetext{
${ }^{64}$ VILLLELA, p. 13.

${ }^{65}$ Assim repudiação islâmica, não homologada pelo STF, citada por BASSO TAMAGNO, p. 84.
} 